\title{
Phytochemical Screening and In vivo Analgesic Activity of Ampelocissus barbata (Wall.) Planch.
}

\author{
Labony Khandokar, Sanjida Rahman Mim and Rasel Babu Rana
}

\author{
Department of Pharmacy, East West University, A/2, Jahurul Islam Avenue \\ Jahurul Islam City, Aftabnagar, Dhaka-1212, Bangladesh
}

(Received: May 29, 2021; Accepted: June 30, 2021; Published (Web): July 15, 2021)

\begin{abstract}
Ampelocissus barbata (Wall.) Planch. is a native medicinal herb in Bangladesh. The present study was aimed at exploring the phytochemical compositions and analgesic potential of the plant in vivo. The methanol extract of A. barbata along with its different fractions were subjected to phytochemical evaluation through established chemical tests for ascertaining the available pool of secondary metabolites within the plant. Eventually, the presence of at least eleven classes of phytoconstituents viz. alkaloids, flavonoids, phenolics, glycosides, saponins, starch, phytosterols, coumarins, tanins, resins and quinones were demonstrated. Among the four partitonates, ethyl acetate soluble fraction of $A$. barbata illustrated the maximum types of secondary metabolites qualitatively. The ability of the crude methanol extract (MEAB) and its ethyl acetate soluble fraction (EAAB) to suppress nociception both centrally and peripherally were investigated in Swiss albino mice by tail immersion method and acetic acid-induced writhing method, respectively. At the $90^{\text {th }}$ minute of the tail immersion study, both MEAB and EAAB administered at the doses of 250 and $500 \mathrm{mg} / \mathrm{kg}$ body weight (MEAB1, MEAB2, EAAB1, EAAB2) exhibited $240.41 \%, 285.34 \%, 302.83 \%$ and $339.60 \%$ elongation of pain response, respectively, in comparison to the standard, pentazocine which effectuated $421.36 \%$ elongation at the same mark. Moreover, the test samples at the same doses as before exhibited reduction of pain sensation by $66.81 \%$, $74.08 \%, 76.81 \%$, and $83.52 \%$, respectively, in the acetic acid-induced writhing response in mice. Both the central and peripheral analgesic potentials of $\mathrm{EAAB}$ were discernibly higher than those of MEAB at both doses. The findings of the study represents the pharmacological potential of this species in appropriate animal model for the first time and provides valid foundation to warrant future scientific endeavors into the plant.
\end{abstract}

Key words: Ampelocissus barbata, phytochemical screening, phytoconstituents, central analgesic, peripheral analgesic.

\section{Introduction}

Plant-derived herbal drugs have always been utilized as sources of medicine to treat various types of ailments throughout the world (Biswas et al., 2010). As natural products illustrated relatively lesser degree of adverse reactions and better safety profiles, development of new therapeutic agents through the isolation of potential bioactive molecules from plant extracts and their subsequent structural modification into lead compounds, became the prime route of drug discovery (Farnsworth et al., 1985). Traditional medicinal systems, especially the Chinese, Indian and Egyptian folk medicines have experienced extensive development over different time periods aided by the information from ethnic groups about the pharmacological benefits of indigenous traditional herbal products (Hasib et al., 2020; Schultes and Raffauf, 1990; Katewa and Galav, 2005). However, only around $8 \%$ of all known plants have been enumerated till date for their medicinal applications and they have also contributed extensively in providing structurally diverse drug molecules and

Corresponding author: Labony Khandokar Email: labony@ewubd.edu

DOI: https://doi.org/10.3329/bpj.v24i2.54710 
novel chemical entities for drug designing and development. So, the preliminary phytochemical investigation is helpful to ascertain the importance of any medicinal plant in order to provide relevant information about the available classes of phytoconstituents as well as structural diversity within the plant (Bari et al., 2021).

Ampelocissus is a large genus consisting of about 100 species classified under the Vitaceae family (grape family). Among them, A. barbata (Wall.) Planch. is native to the Indian subcontinent and is utilized extensively for its medicinal values. It was originally identified and described from Sylhet, Bangladesh by Nathaniel Wallich (Roxburgh et al., 1820). The plant is also distributed widely in many regions of Southern India viz. West Bengal, Assam, Meghalaya, Tripura, Mizoram, Nagaland, Darjeeling, Sikkim, Uttar Pradesh, Arunachal Pradesh, Bhutan, Myanmar, Vietnam Thailand, Andaman and Nicobar islands (India Biodiversity Portal, 2021). Within Bangladesh, the plant grows widely in the forests of Chittagong, Chittagong Hill Tracts, Tangail and Sylhet (Flora of Bangladesh, 2019). The common Bengali name of the plant is "Amoluka", "Gowalialata" or "Jungli angoor" and it is generally known as "Panibel" in Hindi (Chaudhuri and Ray, 2020; Flora of Bangladesh, 2019). It grows as shrub for as long as 15 meters in the form of herbaceous climber. Roots are tuberous in nature. Simple leaves are formed as entire or lobed or digitately 3-5 foliolate, flowers are numerous, small in size and normally deep reddish in color and fruits are spherical, black and normally seeded (Chaudhuri and Ray, 2020; Pednekar, 2013). In Bangladesh, the local medicinal practitioners as well as the common people use different parts of $A$. barbata for treating various diseases including swellings, pains, and jaundice. Crushed stems and tubers are applied topically and rubbed for attenuating edema and pain sensation. In Khagrachari district, decoction of the leaves mixed with water is used as a bath water in jaundice treatment (Morshed, 2013). Juice of its roots mixed kernel of coconut is employed as a depurative and aperients. Furthermore, root juice is used as blood purifier and diuretic to ensure removal of waste products from body.
Moreover, root paste is utilized in the treatment of fractures, sprains, bruises, injuries, wounds (Morshed, 2013).

Numerous phytochemical as well as in vitro and in vivo pharmacological studies have been conducted on A. latifolia and few other related species, but any study on A. barbata is not reported yet. As this plant is native to our country and have been widely recorded for its usefulness in treating pain, this study have endeavored to explore its analgesic potential in vivo as well as its phytochemical composition accordingly.

\section{Materials and Methods}

Drugs and reagents: Glacial acetic acid, lead acetate, ferric chloride, sulphuric acid, acetic anhydride, hydrochloric acid (dilute), chloroform, iodine, sodium hydroxide, nitric acid, ammonia, ammonium hydroxide, Meyer's reagent, Dragendoff's reagent, Fehling's solution A and B, Ninhydrin reagent, copper sulphate, acetic acid $(0.6 \%)$, methanol were procured from authorized and trustworthy chemical suppliers from Dhaka, Bangladesh. Authentic samples of diclofenac sodium and pentazocine along with normal saline were obtained from leading pharmaceutical companies of the country. Procurement of all the reagents in analytical grade was strictly ensured.

Preparation of plant material: Fresh whole plants of A. barbata were collected from Moulvibazar area of Sylhet district of Bangladesh in September 2019. Adequate plant identification was ensured by experts from the Bangladesh National Herbarium located at Mirpur, Dhaka. For future reference and correspondence, a voucher specimen number (48328) was issued from the same institution. After collection, the whole plants were cleaned for any adhering dirts, followed by shade-drying for adequate time period. Dried plant parts were subjected to extensive grinding to obtain a coarse powder that can enhance extraction efficiency.

Extraction and partitioning: Around 700 gm of powdered plant parts was placed in an amber colored bottle to soak in adequate volume (around 2.4 liters) 
of distilled methanol for fourteen days along with occasional agitation to ensure maximum extraction of phytochemicals. After the maceration process, the mixture was initially filtered using sterilized cotton followed by further clarification through the Whatman (No. 1) filter paper. Subsequently, the resultant filtrate was introduced into a rotary evaporator maintained at low temperature and pressure in order to minimize the large volume of solvent. Eventually, the filtrate was reduced to a very concentrated mass that was then transferred to a preweighted beaker and the solvent was allowed to evaporate completely in the following days. Weighing the beaker allowed for the determination of the total weight of extract and $5 \mathrm{gm}$ of the extract was subjected to modified Kupchan partitioning protocol as developed by Van Wagenen et al. (1993) to acquire four different fractions of varying polarity viz. $n$-hexane (HSF), dichloromethane (DCMSF), ethyl acetate (EASF) and aqueous soluble (AQSF) fractions. All Kupchan partitionates along with crude extract were subjected to phytochemical screening and evaluated for in vivo analgesic activity.

Phytochemical screening: The freshly prepared crude methanol extract of $A$. barbata and its subsequent fractions (HSF, DCMSF, EASF, AQSF) were subjected to qualitative chemical methods for determining the presence of alkaloids (Meyer's and Dragendoff's test), flavonoids and tannins (Lead acetate test), anthraquinones (Chloroform layer test), coumarin (Alcoholic test), quinone (Sulfuric acid test), glycosides and phenolic compounds (Ferricchloride test), cardiac glycosides (Ammonia test), saponins (Frothing test), phytosterol (LiebermannBurchard test), resins (Acetic anhydride test), amino acids (Ninhydrin test), carbohydrates (Fehling's test), starch (Iodine test) and proteins (Biuret test) (Onwukaeme et al., 2007; Seow et al., 2013).

Experimental animals: Both male and female Swiss albino mice of aged around 4-5 weeks were procured from the International Centre for Diarrheal Disease Research, Bangladesh (icddr,b) Dhaka. Thirty six animals were kept at the animal house of Department of Pharmacy, East West University, which is constantly maintained at standard laboratory conditions, i.e. $55-65 \%$ relative humidity, room temperature at $25.0 \pm 2{ }^{\circ} \mathrm{C}$, and half day light-half day dark cycle. The animals were routinely supplied with icddr,b formulated standard diet along with unlimited tap water and their weight was maintained in the range of 25-35 g. For each in vivo analgesic evaluation, eighteen experimental animals were randomly categorized into six equal groups of three mice in each, representing one positive control, one negative control and four test groups.

Determination of central analgesic activity: As developed by Dewey et al. (1970), the tail immersion method, alternatively known as the tail flick method, was employed to evaluate the pain reducing effects of A. barbata. As part of the process, four test groups received the extracts i.e. MEAB and EAAB at either 250 or $500 \mathrm{mg} / \mathrm{kg}$ body weight doses. Simultaneously, the positive and negative controls were administered with standard drug pentazocine intraperitoneally at the dose of $10 \mathrm{mg} / \mathrm{kg}$ body weight and normal saline orally at the dose of $10 \mathrm{ml} / \mathrm{kg}$, respectively. Administration of the standard or sample was followed by a thirty minutes time lapse to ensure adequate absorption into systemic circulation. For the tail immersion phase, warm water was constantly maintained at $55^{\circ} \mathrm{C}$ and the tip of the tail of each mice $(1-2 \mathrm{~cm})$ was submerged in it to observe the response. The time required by each mice to realize the warmth of the water followed by the withdrawal of their tails from it, was recorded as the response time. However, a lack of observed response from the mice for at least twenty seconds was considered as complete suppression of pain response and the process was immediately discontinued to avoid any damage to the mice. Responses from the mice were recorded at 30, 60 and 90 minutes of administration and respective percent (\%) elongations of pain responses were determined accordingly.

Percent elongation $(\%)=\left(\mathrm{T}_{\mathrm{T}} / \mathrm{T}_{\mathrm{C}}-1\right) \times 100 \%$

where, $T_{T}$ and $T_{C}$ represent the average tail immersion time of the test groups and the control, respectively. 
Determination of peripheral analgesic activity: The abilities of both A. barbata extract and fraction to effectuate peripheral analgesia were investigated through acetic acid-induced writhing model in mice (Whittle, 1964). In this study, mice of positive control group received standard diclofenac sodium $(10 \mathrm{mg} / \mathrm{kg}$ body weight) orally whereas negative control group received oral administration of normal saline solution at the dose of $10 \mathrm{ml} / \mathrm{kg}$ bw. Among the four test groups, two groups were received methanol extract of A. barbata (MEAB1, MEAB2) and another two groups were given ethyl acetate fraction of $A$. barbata (EAAB1, EAAB2) orally at doses of 250 and $500 \mathrm{mg} / \mathrm{kg}$ of body weight, respectively. Thirty minutes after the administration of the control or sample, pain was induced in each mouse through intraperitoneal administration of $0.6 \%$ (v/v) acetic acid solution at the dose of $10 \mathrm{ml} / \mathrm{kg}$ bw. Afterwards, each mouse was observed individually in order to record the number of writhing demonstrated by them for 15 minutes. However, complete writhing was not always exhibited by the mice and each incomplete writhing movement was registered as half-writhing. Accordingly, one count of writhing was registered in place of two incomplete or halfwrithing. A significant decrease in writhing counts as demonstrated by the tested animal contrasted with that of the negative control group was considered as successful induction of analgesia. The percent (\%) inhibition of writhing response, which represented peripheral analgesic response, was calculated using the following formula:

Percent Inhibition $(\%)=\left(1-\mathrm{W}_{\mathrm{T}} / \mathrm{W}_{\mathrm{C}}\right) \times 100 \%$

where, $\mathrm{W}_{\mathrm{C}}$ and $\mathrm{W}_{\mathrm{T}}$ represent the mean count of writhing responses exhibited by the mice of control and test groups, respectively.

\section{Results and Discussion}

Phytochemical screening: Preliminary phytochemical investigation may assist in the enumeration of the importance the plant medicinally by indicating the available classes of secondary metabolites in the plant parts. The availability of the secondary metabolites such as alkaloids, glycosides, cardiac glycosides, flavonoids, tannins, carbohydrates, anthraquinones, amino acids, proteins, phenolic compounds, saponins, resins, phytosterols, coumarins and quinones, in varying amount in the different fractions of A. barbata crude extract have been enumerated in Table 1.

Analgesic activity: In the tail immersion method, both the MEAB and EAAB demonstrated dosedependent induction of central analgesia in experimental mice and the results have been presented in Table 2. EAAB exhibited more potent pain suppression compared to that of MEAB at both experimental doses. Furthermore, both of their activities were comparable to that of standard pentazocine which demonstrated pain suppression of $421.36 \%$ at $90^{\text {th }}$ minute of intervention. Both 250 and $500 \mathrm{mg} / \mathrm{kg}$ body weight doses of MEAB and EAAB attenuated the pain response significantly $(\mathrm{p}<0.01)$ by $240.41 \%, 285.34 \%, 302.83 \%$ and $339.60 \%$, respectively, at the same time interval. Among the samples, the maximum extent of central analgesia $(339.60 \%)$ was illustrated by EAAB at $500 \mathrm{mg} / \mathrm{kg}$ body weight dose.

Inhibitory effect of the methanol extract (MEAB1 and MEAB2) as well as the ethyl acetate fraction (EAAB1 and EAAB2) of A. barbata on the acetic acid-induced writhing of mice has been delineated in Table 3. Oral administration of both MEAB and EAAB at the doses of 250 and $500 \mathrm{mg} / \mathrm{kg}$ body weight significantly ( $\mathrm{p}<0.01$ ) abated abdominal writhing response in mice following a dose dependent manner. The percent inhibition of pain responses by $66.81 \%, 74.08 \%, 76.81 \%$, and $83.52 \%$ were demonstrated by MEAB and EAAB at both doses, respectively, whereas the positive control (diclofenac sodium, $10 \mathrm{mg} / \mathrm{kg}$ ) showed $85.51 \%$ peripheral analgesia.

Preliminary phytochemical screening revealed the presence of alkaloids, flavonoids, phenolics, glycosides, tannins, saponins, resins, coumarins, quinones, starch, and phytosterols in the methanol extract of A. barbata. Among the four partitionates, the ethyl acetate soluble fraction of A. barbata expressed the maximum content of phytochemical 
classes except coumarins, phytosetrols and saponins. Rich presence of flavonoids and phenolics within the fractions indicates that this plant may possess potent free radical scavenging properties which may translate into anti-oxidative activity and can prevent oxidative damage of macromolecules (Doss, 2009; Seow et al., 2012). Similarly, such antioxidant property can also be attributed to anti-cancer potentials of the plant (Doss, 2009). It has been demonstrated previously that tannins exhibits potential cytotoxic, anti-proliferative and anticancer effects (Aguinaldo et al., 2005). Moreover, saponins have been extensively recognized for their potential

Table 1. Phytochemical compositions of $A$. barbata extracts.

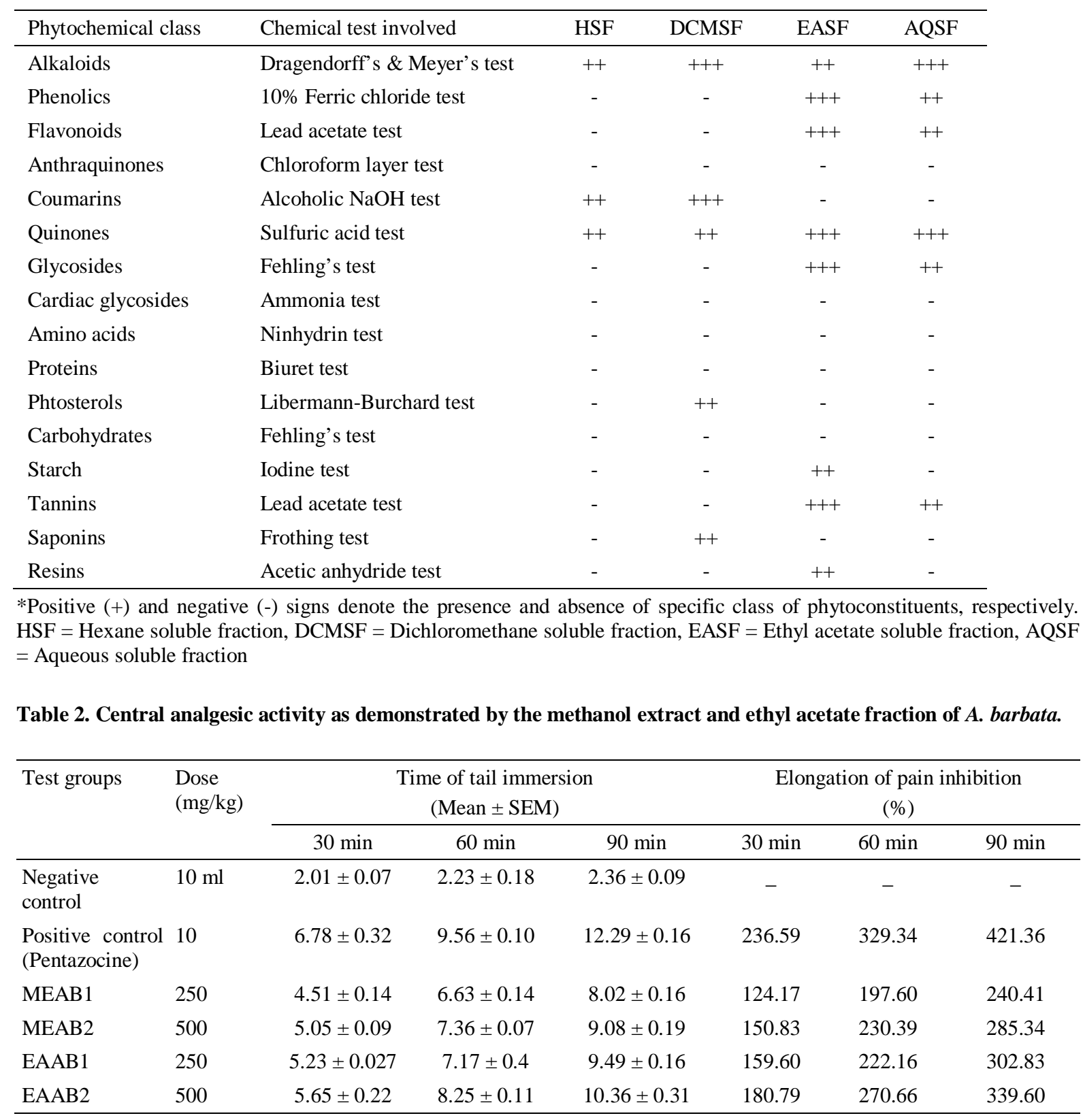

All experimental values have been presented as mean \pm standard error of mean for $n=3$ mice. Statistical significance of $p<$ 0.01 was calculated for all responses compared against standard. 
Table 3. Peripheral analgesic activity as demonstrated by the methanol extract and ethyl acetate fraction of $A$. barbata.

\begin{tabular}{lccc}
\hline Test groups & $\begin{array}{c}\text { Dose } \\
(\mathrm{mg} / \mathrm{kg} \text { bw })\end{array}$ & $\begin{array}{c}\text { Average number of writhing } \\
(\text { Mean } \pm \text { SEM })\end{array}$ & $\begin{array}{c}\text { Inhibition of pain response } \\
(\%)\end{array}$ \\
\hline $\begin{array}{l}\text { Negative Control } \\
\text { (Normal saline) }\end{array}$ & $10 \mathrm{ml}$ & $64.5 \pm 2.08$ & - \\
\hline Positive control & & $9.33 \pm 0.441$ & 85.54 \\
(Diclofenac sodium) & 10 & & \\
MEAB1 & 250 & $21.33 \pm 1.17$ & 66.81 \\
MEAB2 & 500 & $16.67 \pm 0.73$ & 74.08 \\
EAAB1 & 250 & $15 \pm 1.26$ & 76.81 \\
EAAB2 & 500 & $10.67 \pm 1.30$ & 83.52 \\
\hline
\end{tabular}

All experimental values have been presented as mean \pm standard error of mean for $n=3$ mice. Statistical significance of $p<$ 0.01 was calculated for all responses compared against standard.

for antioxidative, anti-inflammatory, hypoglycemic and anticancer activities (Rathore et al., 2012). The presence of such secondary metabolites provides scientific basis for promising biological activities of A. barbata extract. Thus, it can be inferred that bioactivity-guided isolation of phytochemicals from this plant is warranted in future to yield potentially lead compounds.

The acetic acid-induced writhing assay in mice have been established as a robust and reliable method for estimating peripheral analgesic activity. Inflammatory responses are often initiated through the liberation of free arachidonic acid secondary to specific stimuli (Ahmed et al., 2006) which then acts as a substrate for cyclooxygenase (COX) enzyme, and undergoes chemical conversion to result in prostaglandin biosynthesis (Duarte et al., 1988). Subsequently, such pro-inflammatory prostaglandin molecules mediates pain sensation in experimental animals. Active phytoconstituents in any plant are capable of attenuating such responses through the suppression of either prostaglandin synthesis or their interaction at receptor sites. Eventually, peripheral analgesia is induced which is illustrated through diminished number of writhing responses (Duarte $e t$ al., 1988; Ferdous et al., 2008). The remarkable capacities of both the methanol extract and ethyl acetate soluble fraction of $A$. barbata in suppressing peripheral pain sensation might be due to the presence of analgesic agents within its phytochemical pool.

The plant also exhibited strong central analgesic action in the tail immersion test. Antagonism of central nociceptors located within the brain and spinal cord, can lead to central analgesic effect (Sharma et al., 2003; Khanna and Bhatia, 2003). Opiates, especially morphine, represent one of the most potent and anciently recognized natural analgesic agent which exert their anti-nociceptive activity by interacting with specific class of central nociceptors known as opioid receptors (Wani et al., 2012). In this assay, both the methanol extract of $A$. barbata and its ethyl acetate soluble fraction effectuated prominent central analgesia as compared to that of pentazocine, a potent analogue of morphine. Hence, the central analgesic activity of $A$. barbata may be attributed to its capacity to interact with opioid receptors and require further investigations in order to validate such estimation.

Therefore, it can be assumed that classes of phytoconstituents that have been confirmed through the qualitative phytochemical screening may be the principal mediators of observed analgesic properties. On that note, noteworthy analgesic properties have been previously attributed to both flavonoids and alkaloids, especially through the suppression of prostaglandin synthesis (Rajnarayana et al. 2001; Rao et al., 1998; Uche et al., 2008) and both of these 
classes have been positively estimated to be present in A. barbata.

\section{Conclusion}

Based on the aforementioned projections, it can be rationally enumerated that the methanol extract of whole plants of $A$. barbata and its Kupchan partionates possess various important classes of secondary metabolites Dose-dependent analgesic activities were observed in both tail immersion test and writhing test, implying significant potentials for central and peripheral analgesia by both the methanol extract and its ethyl acetate soluble fraction. However, extensive and detailed phytochemical investigations into the plant are required in future in order to identify and characterize potential bioactive components responsible for such central and peripheral analgesic activities.

\section{References}

Aguinaldo A.M., Espeso E.I., Guevara B.Q., Nonato M.G. 2005. Phytochemistry. In: Guevara BQ (ed.) A Guidebook to Plant Screening: Phytochemical and Biological. University of Santo Tomas, Manila, Philippines.

Ahmed F., Hossain M.H., Rahman A.A., Shahid I.Z. 2006. Antinociceptive and sedative effects of the bark of Cerbera odollam Gaertn. Orient. Pharm. Exp. Med. 6, 344-348.

Bari, M.S., Khandokar, L., Haque, E., Romano, B., Capasso, R., Seidel, V., Haque, M.A. and Rashid, M.A. 2021. Ethnomedicinal uses, phytochemistry, and biological activities of plants of the genus Gynura. J. Ethnopharmacol. 271, 113834.

Biswas, A., Bari, M.A., Roy, M. and Bhadra, S.K. 2010. Inherited Folk pharmaceutical knowledege of tribal people in the Chittagong Hill tracts, Bangladesh. Indian J. Trad. Knowledge. 9, 77-89.

Chaudhuri, A. and Ray, S. 2020. Cytotoxic and antiproliferative activities of aqueous extract from aerial parts of Ampelocissus latifolia (Roxb.) Planch. on Dalton's lymphoma cells. J. King Saud Univ. Sci. 32, 1978-1985.

Dewey, W.L., Harris, L.S., Howes, J.F. and Nuite, J.A. 1970. The effect of various neurohumoral modulators on the activity of morphine and the narcotic antagonists in the tail-flick and phenylquinone tests. $J$. Pharmacol. Exp. Ther. 175, 435-442.
Doss, A., 2009. Preliminary phytochemical screening of some Indian medicinal plants. Anc. Sci. Life. 29, 12.

Duarte I.D.G., Nakamura M., Ferreira S.H. 1988. Participation of the sympathetic system in acetic acidinduced writhing in mice. Braz. J. Med. Biol. Res. 21, 341-343.

Farnsworth, N.R., Akerele, O., Bingel, A.S., Soejarto, D.D. and Guo, Z. 1985. Medicinal plants in therapy. Bull. WHO. 63, 965-981.

Ferdous M., Rouf R., Shilpi J.A., Uddin S.J. 2008. Antinociceptive activity of the ethanolic extract of Ficus racemosa Linn. (Moraceae). Orient. Pharm. Exp. Med. 8, 93-96.

Flora of Bangladesh. 2019. Published on the Internet; http://bnh-flora.gov.bd/ (last accessed $17^{\text {th }}$ June, 2021).

Hasib, M.S., Bari, M.S., Chowdhury, A., Hossain, M.A. and Rashid, M.A. 2020. Vachellia farnesiana (L.) Wight \& Arn. gGrowing in Bangladesh exerts in-vitro antioxidant and in-vivo analgesic and anti-diarrheal activities. Bangladesh Pharm. J. 23, 181-186.

India Biodiversity Portal, Species Page: \{Ampelocissus barbata (Wall.) Planch.\}. Published on the Internet; https://indiabiodiversity.org/biodiv/species/show/2520 45 (last accessed 17th June, 2021).

Khanna, N. and Bhatia, J. 2003. Antinociceptive action of Ocimum sanctum (Tulsi) in mice: possible mechanisms involved. J. Ethnopharmacol. 88, 293- 296.

Katewa, S.S. and Galav, P.K. 2005. Traditional herbal medicines from Shekhawati region of Rajasthan. Indian J. Trad. Knowledge. 4, 237-245.

Morshed, A.J. 2013. A survey of medicinal plants as regards to their uses by the tribal practitioners in the Chittagong hill tracts of Bangladesh to check various diseases. Hamdard Med. 56, 18-40.

Onwukaeme D.N., Ikuegbvweha T.B. and Asonye C.C. 2007. Evaluation of phytochemical constituents, antibacterial activities and effect of exudate of Pycanthus Angolensis Weld Warb (Myristicaceae) on corneal ulcers in rabbits. Trop. J. Pharm. Res. 6, 725730 .

Pednekar, P.A. and Raman, B. 2013. Antimicrobial and antioxidant potential with FTIR analysis of Ampelocissus latifolia (Roxb.) Planch. leaves. Asian J. Pharm. Clin. Res. 6, 157-62.

Rajnarayana K., Reddy M.S., Chaluvadi M.R., Krishna D.R. 2001. Biflavonoids classification, pharmacological, biochemical effects and therapeutic potential. Indian J. Pharmacol. 33, 2-16. 
Rathore, S.K., Bhatt, S.H.A.S.H.A.N.K., Dhyani, S. and Jain, A. 2012. Preliminary phytochemical screening of medicinal plant Ziziphus mauritiana Lam. fruits. Int. J. Curr. Pharm. Rev. Res. 4, 160-162.

Rao M.R., Rao Y.M., Rao A.V., Prabhkar M.C., Rao C.S., Muralidhar N. 1998. Antinociceptive and antiinflammatory activity of a flavonoid isolated from Caralluma attenuate. J. Ethnopharmacol. 62, 63-66.

Roxburgh, W., Carey, W. and Wallich, N. 1820. Flora indica.

Schultes, R.E. and Raffauf, R.F. 1990. The healing forest: medicinal and toxic plants of the northwest Amazonia. Dioscorides Press, Oregon, 484.

Sharma, S., Jain, N.K. and Kulkarni, S.K. 2003. Inhibition of COX-1 enzyme potentiate opioid-induced antinociception in animal model of central nociception. Indian J. Pharmacol. 35, 21-26.

Seow, L.J., Beh, H.K., Ibrahim, P., Sadikun, A. and Asmawi, M.Z. 2012. Antimicrobial activity of Gynura segetum's leaf extracts and its active fractions. Cell Med. 2, 20-21.
Seow, L.J., Beh, H.K., Sadikun, A. and Asmawi, M.Z. 2013. Preliminary phytochemical and physicochemical characterization of Gynura segetum (Lour) Merr (Compositae) leaf. Trop. J. Pharm. Res. 12, 777-782.

Uche F.I., Aprioku J.S. 2008. The phytochemical constituents, analgesic and anti-inflammatory effects of methanol extract of Jatropha curcas leaves in mice and Wister albino rats. J. Appl. Sci. Environ. Manage. 12, 99-102.

VanWagenen, B.C., Larsen, R., Cardellina, J.H., Randazzo, D., Lidert, Z.C. and Swithenbank, C. 1993. Ulosantoin, a potent insecticide from the sponge Ulosa ruetzleri. J. Org. Chem. 58, 335-337.

Wani, T.A., Kumar, D., Prasad, R., Verma, P.K., Sardar, K.K., Tandan, S.K. and Kumar, D. 2012. Analgesic activity of the ethanolic extract of Shorea robusta resin in experimental animals. Indian J. Pharmacol. 44, 493-499.

Whittle, B.A. 1964. The use of changes in capillary permeability in mice to distinguish between narcotic and non-narcotic analgesics. Br. J. Pharmacol. Chemother. 22, 246-253. 